\title{
Krypton Gas for High Quality Single Wall Carbon Nanotubes Synthesis by KrF Excimer Laser Ablation
}

\author{
Jasim Al-Zanganawee, ${ }^{1,2}$ Adrian Katona, ${ }^{1}$ Calin Moise, ${ }^{1}$ \\ Dionezie Bojin, ${ }^{1}$ and Marius Enachescu ${ }^{1,3}$ \\ ${ }^{1}$ Center for Surface Science and Nanotechnology (CSSNT), Politehnica University of Bucharest, 060042 Bucharest, Romania \\ ${ }^{2}$ Physics Department, College of Science, University of Diyala, Iraq \\ ${ }^{3}$ Academy of Romanian Scientists, Splaiul Independentei 54, 050094 Bucharest, Romania \\ Correspondence should be addressed to Jasim Al-Zanganawee; jasim_mansoor@yahoo.com
}

Received 25 August 2015; Accepted 28 September 2015

Academic Editor: Yuan Chen

Copyright (C) 2015 Jasim Al-Zanganawee et al. This is an open access article distributed under the Creative Commons Attribution License, which permits unrestricted use, distribution, and reproduction in any medium, provided the original work is properly cited.

\begin{abstract}
We report for the first time the production of single wall carbon nanotubes (SWCNTs) by KrF excimer laser ablation method under the krypton gas atmosphere. For the ablation experiment $450 \mathrm{~mJ}$ energy and $30 \mathrm{~Hz}$ repetition rate $\mathrm{KrF}$ excimer laser was used, and the target was prepared with the following composition: $0.6 \% \mathrm{Ni}, 0.6 \% \mathrm{Co}$, and $98.8 \% \mathrm{C}$ (atomic percentage). The ablation product was characterized by confocal Raman microspectroscopy, transmission electron microscopy (TEM), scanning electron microscopy (SEM), and thermogravimetric analysis (TGA). The SWCNTs obtained are a mixture of semiconducting and metallic types with narrow diameters distribution of 1.26 to $1.49 \mathrm{~nm}$, are micrometers long, and contain low amount of graphite and amorphous carbon.
\end{abstract}

\section{Introduction}

Since Iijima discovered the multiwall carbon nanotubes in 1990 [1] and especially in 1993 when Iijima and Ichihashi discovered the single wall carbon nanotubes [2], they are still attracting the interests of great number of scientific research groups and industries around the world because of their exceptional electrical [3], mechanical [4], thermal [5], and magnetic [6] properties. The CNTs have been used in different types of applications such as biosensors [7], chemical sensors [8], scanning microscope tips [9], nanoelectronics [10], third generation solar cell [11], and hydrogen storage [12].

Many different techniques have been used and developed for production of carbon nanotubes such as chemical vapour deposition (CVD) [13], arc discharge [14], and laser ablation techniques [15]. Pulse laser ablation method was observed to yield specifically high quality and high purity [16] and high yield [17] of single wall carbon nanotubes. Several types of lasers have been used to produce SWCNTs such as Nd:YAG laser [16, 18], $\mathrm{CO}_{2}$ laser [15], $\mathrm{XeCl}$ excimer laser [19], and $\mathrm{KrF}$ excimer laser [20-22]. Parameters such as laser wavelength, carrier gas, ablation temperature, or metal catalysts content of the target have been studied for the optimization of PLA method [22]. For example, the furnace temperature and the gas flow velocity can influence the diameter distribution of SWCNTs. By increasing the furnace temperature or the gas flow velocity, SWCNTs with larger diameter distribution can be produced [23].

To the best of our knowledge, there are no reports in the literature of using krypton gas for the synthesis of single wall carbon nanotubes using $\mathrm{KrF}$ excimer laser ablation. In this work, we report the synthesis of single wall carbon nanotubes with narrow diameter distribution (1.26-1.49 nm) and few micrometers in length by using $\mathrm{KrF}$ excimer laser ablation with wavelength of $248 \mathrm{~nm}$ in krypton atmosphere as carrier gas.

\section{Materials and Methods}

The $\mathrm{KrF}$ excimer laser used for the ablation was produced by Coherent COMPex Pro 205 equipment, having the wavelength of $248 \mathrm{~nm}$ and the pulse period of $20 \mathrm{~ns}$. In our study we used a laser energy of $450 \mathrm{~mJ}$ and $30 \mathrm{~Hz}$ repetition rate. 


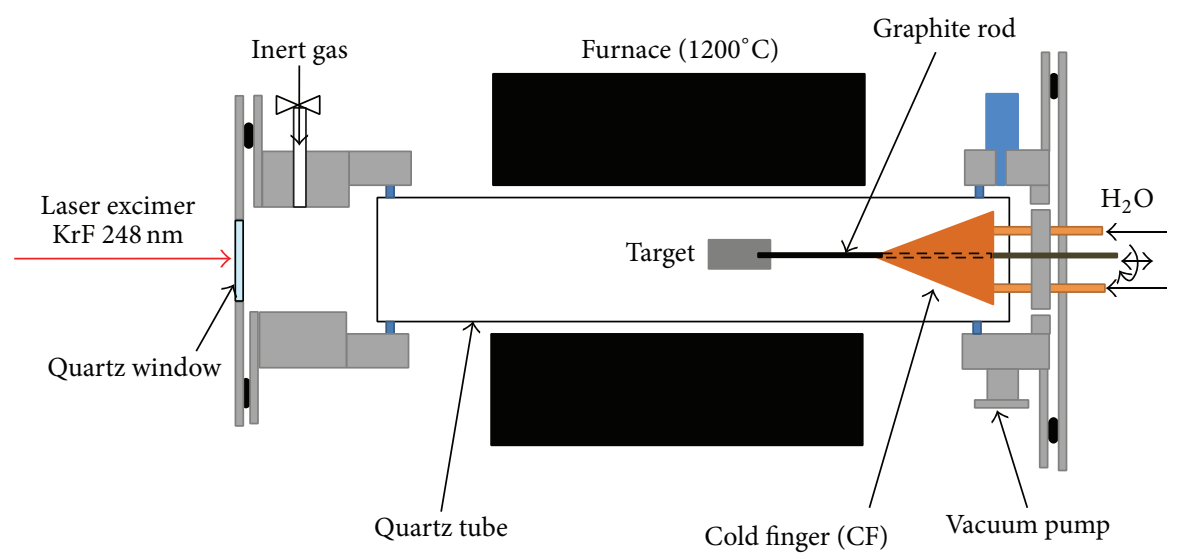

Figure 1: Ablation chamber design [22, 23].

The laser ablation experiment was carried out in a customdesigned installation depicted in Figure $1[22,24]$.

The ablation parameters like temperature, pressure, and laser repetition rate were selected based on the previous optimization studies done in our group [22]. The oven temperature, pressure, and ablation time of the experimental work were $1100^{\circ} \mathrm{C}, 500$ Torr, and 60 minutes, respectively.

The laser ablation starts by passing the laser beam through a UV transparent quartz window and enters into the quartz tube hitting the target, when the target material begins to be ablated. The target was rotated during ablation with constant speed to get uniform ablation. Then the inert gas, which enters from the left-up side of the reaction chamber, moves through the quartz tube to the heated area at $1100^{\circ} \mathrm{C}$ where the reaction takes place, transporting the ablation product toward a copper condenser called cold finger (CF), where it will be deposited as a black soot. The cold finger was cooled down using $12^{\circ} \mathrm{C}$ water supplied by a chiller. The quartz tube of the reaction chamber was $1260 \mathrm{~mm}$ long, with the internal diameter of $50 \mathrm{~mm}$. The inert atmosphere and the transportation of the ablated material to the CF were maintained by using the krypton gas at $70 \mathrm{~L} / \mathrm{h}$ flow rate.

Our system has some special technical features:

(i) The length of the oven was doubled compared with previous designs $[16,25]$, to ensure a more uniform temperature in the ablation reactor, allowing the product to travel longer time in the constant heated zone favoring the growth of the SWCNTs.

(ii) The cold finger is longer $(260 \mathrm{~mm})$ with a higher surface than the previous one [22], reducing the temperature gradient over its length and improving the capture of the product.

(iii) The attached ALICAT flow meter controller allows controlling accurately the flow rate of the carrier gas over a wide range $0-10$ NPLM with a resolution of 0.01 .

The target containing $\mathrm{C}$, $\mathrm{Co}$, and $\mathrm{Ni}$ was prepared by following a recipe developed by Professor Enachescu's group. This recipe involves the mixing of graphite cement (GC
8010-B from Metal Forming Lubricants) with Co and $\mathrm{Ni}$ metal catalysts powder (Sigma Aldrich), with the following composition $0.6 \% \mathrm{Ni}, 0.6 \% \mathrm{Co}$, and $98.8 \% \mathrm{C}$ (atomic percentage). The mixture was transferred into a Teflon mold (20 $\mathrm{mm}$ diameter) and then cured 4 hours at $130^{\circ} \mathrm{C}$ in air to increase the mechanical strength. Further another heat treatment of the target was applied for one hour at $800^{\circ} \mathrm{C}$ in inert atmosphere to remove all the remaining organic compounds.

After ablation, the raw product soot was collected from the copper cold finger. The abundance of single wall carbon nanotubes in the collected product was investigated using confocal micro-Raman spectroscopy, scanning electron microscopy (SEM) and TEM, and thermogravimetric analysis (TGA).

\section{Results and Discussion}

3.1. Raman Spectroscopy Analysis. To identify the SWCNTs, the ablation product was analyzed by confocal Raman microspectroscopy using a Horiba Labram 800 instrument equipped with two laser wavelengths: $532 \mathrm{~nm}$ and $633 \mathrm{~nm}$. The Raman spectra were recorded using both excitation wavelengths. The spectrum of the ablation product was compared with the commercial SWCNTs from Sigma as shown in Figure 2. The Raman spectra present three main regions specific to SWCNTs: radial breathing mode (RBM) and $\mathrm{D}$ and $\mathrm{G}$ bands which are further analyzed.

3.1.1. RBM Band Analysis. For the raw ablation product using the green laser ( $532 \mathrm{~nm}$ and $2.33 \mathrm{eV}$ ), two vibrational frequency peaks were found in the RBM band of the Raman spectra, each peak corresponding to a diameter distribution. Using red laser $(633 \mathrm{~nm}$ and $1.96 \mathrm{eV})$, one vibrational frequency peak was found, corresponding to single diameter distribution (Figure 3). Table 1 shows the calculated diameters of the synthesized SWCNTs.

For the commercial product using the green laser, one peak was found (Figure 2) corresponding to a single diameter distribution, while using the red laser two peaks were found 


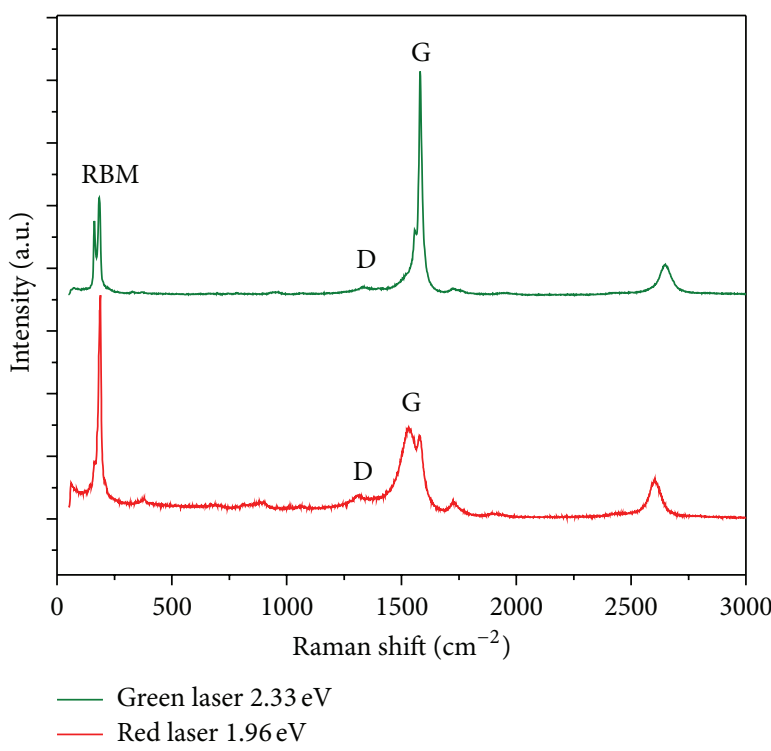

(a)

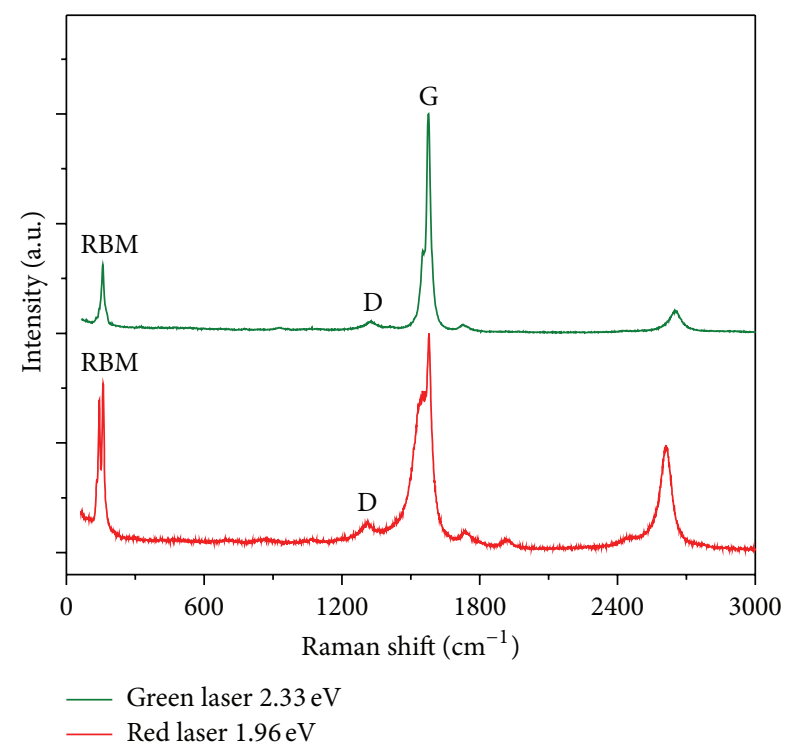

(b)

FIGURE 2: Raman spectra of the raw ablation product (a) and the commercial SWCNTs (b) recorded with green laser (532 nm, top spectrum) and red laser $(633 \mathrm{~nm}$, bottom spectrum).

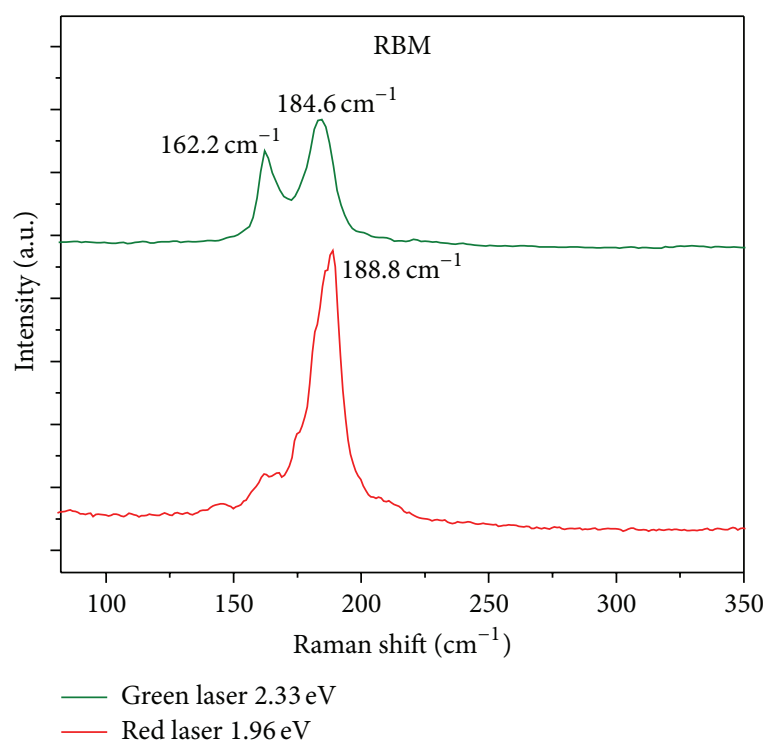

(a)

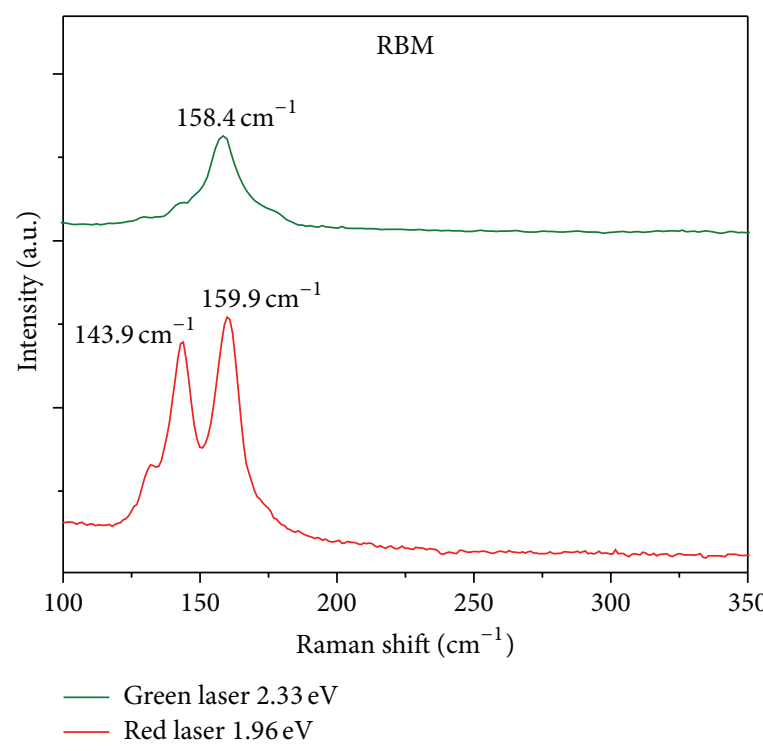

(b)

FIGURE 3: RBM band of the Raman spectra for the raw ablation product (a) and the commercial SWCNTs recorded with green laser (532 nm, top spectrum) and red laser ( $633 \mathrm{~nm}$, bottom spectrum).

(Figure 2) corresponding to two diameters distribution, their values being listed in Table 2.

The vibrational frequency in the radial direction strongly depends on the diameter of the nanotubes, described by [26]

$$
d=\frac{c_{1}}{\left(\omega-c_{2}\right)},
$$

where $\omega$ is frequency of vibrations in the radial direction $\left[\mathrm{cm}^{-1}\right] ; c_{1}$ and $c_{2}$ are constants $\left[\mathrm{cm}^{-1}\right]: c_{1}=215\left[\mathrm{~cm}^{-1}\right]$ and $c_{2}=18\left[\mathrm{~cm}^{-1}\right] ; d$ is the diameter of the nanotubes $[\mathrm{nm}]$.

Equation (1) was used to calculate the diameters of the SWCNTs and their values are summarized in Tables 1 and 2.

The diameters of individual SWCNTs obtained in the laser ablation have been estimated to be between $1.26 \mathrm{~nm}$ 


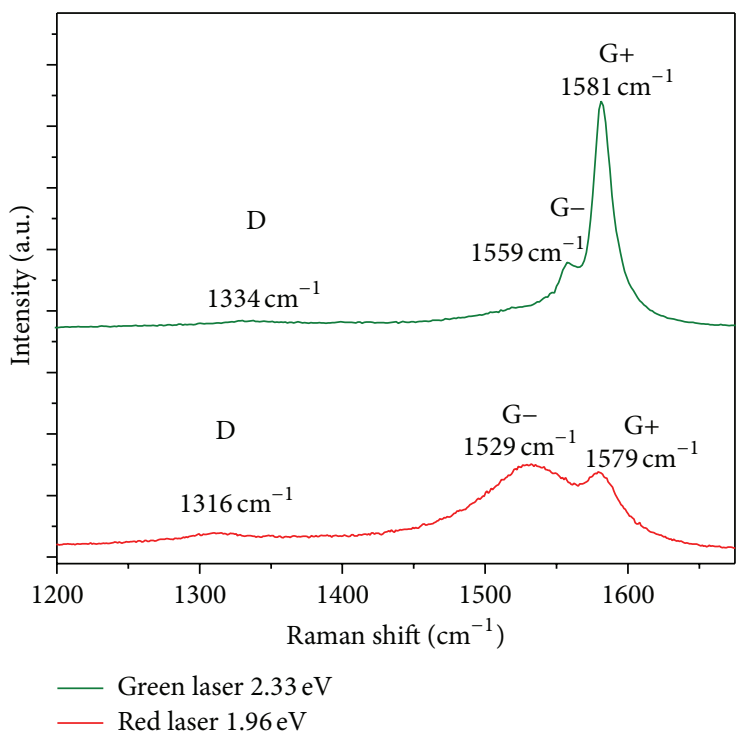

(a)

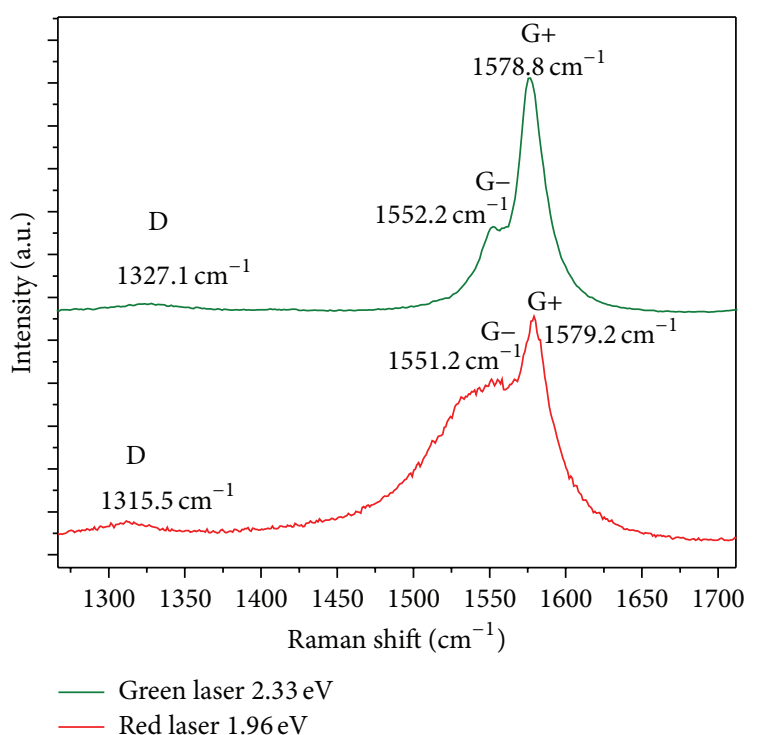

(b)

Figure 4: D and G bands of the Raman spectra of the raw ablation product (a) and the commercial SWCNTs (b) recorded with green laser $(532 \mathrm{~nm}$, top spectrum) and red laser $(633 \mathrm{~nm}$, bottom spectrum).

TABLE 1: Calculated diameter of the synthesized SWCNTs using (1).

\begin{tabular}{lcc}
\hline Laser & $\begin{array}{c}\text { Vibration frequency } \\
{\left[\mathrm{cm}^{-1}\right]}\end{array}$ & $\begin{array}{c}\text { SWCNTs diameter } \\
{[\mathrm{nm}]}\end{array}$ \\
\hline Green $532 \mathrm{~nm}(2.33 \mathrm{eV})$ & 162.2 & 1.49 \\
& 184.6 & 1.29 \\
Red $633 \mathrm{~nm}(1.96 \mathrm{eV})$ & 188.8 & 1.26 \\
\hline
\end{tabular}

TABLE 2: Calculated diameter of the commercial SWCNTs using (1).

\begin{tabular}{lcc}
\hline Laser & $\begin{array}{c}\text { Vibration frequency } \\
{\left[\mathrm{cm}^{-1}\right]}\end{array}$ & $\begin{array}{c}\text { SWCNTs diameter } \\
{[\mathrm{nm}]}\end{array}$ \\
\hline Green $532 \mathrm{~nm}(2.33 \mathrm{eV})$ & 158.4 & 1.53 \\
& 143.9 & 1.71 \\
Red $633 \mathrm{~nm}(1.96 \mathrm{eV})$ & 159.9 & 1.52 \\
\hline
\end{tabular}

and $1.49 \mathrm{~nm}$, while for the commercial SWCNTs they were between $1.52 \mathrm{~nm}$ and $1.71 \mathrm{~nm}$. Similar values have been reported by other authors for the SWCNTs obtained by laser ablation of targets with a similar composition [25].

3.1.2. $D$ and $G$ Bands Analysis. In the range of $1300-$ $1600 \mathrm{~cm}^{-1}$ two bands were identified for both products, respectively, D and G bands, which are specific for SWCNTs (Figure 4) and help in the SWCNTs identification. Their values are shown in Tables 3 and 4 . D band is characteristic for scattering on $\mathrm{sp}^{3}$ type carbon atoms; therefore, this signal is assigned to the amorphous carbon content in the sample and the defects in the nanotubes structure [27], while G band is due to the presence of $\mathrm{sp}^{2}$ carbon in the nanotubes structure. Hence, the ratio of the integrated intensity of D and G bands, $I_{\mathrm{D}} / I_{\mathrm{G}}$, is a measure of the quality of SWCNTs which shows the purity and the defects [28]. This ratio has a very low value
TABLE 3: Raman shift, $I_{\mathrm{D}} / I_{\mathrm{G}}$ and $I_{\mathrm{G}-} / I_{\mathrm{G}+}$ values for the ablation product.

\begin{tabular}{|c|c|c|c|c|c|}
\hline \multirow{2}{*}{ Laser } & \multirow{2}{*}{$\begin{array}{l}\text { D band } \\
{\left[\mathrm{cm}^{-1}\right]}\end{array}$} & \multicolumn{2}{|c|}{$\mathrm{G}$ band $\left[\mathrm{cm}^{-1}\right]$} & \multirow{2}{*}{$I_{\mathrm{D}} / I_{\mathrm{G}}$} & \multirow{2}{*}{$I_{\mathrm{G}-} / I_{\mathrm{G}+}$} \\
\hline & & G- & $\mathrm{G}+$ & & \\
\hline Green $532 \mathrm{~nm}(2.33 \mathrm{eV})$ & 1334 & 1559 & 1581 & 0.004 & 0.43 \\
\hline Red $633 \mathrm{~nm}(1.96 \mathrm{eV})$ & 1316 & 1526 & 1579 & 0.004 & 2.11 \\
\hline
\end{tabular}

TABLE 4: Raman shift, $I_{\mathrm{D}} / I_{\mathrm{G}}$ and $I_{\mathrm{G}-} / I_{\mathrm{G}+}$ values for the commercial SWCNTs.

\begin{tabular}{lccccc}
\hline \multirow{2}{*}{ Laser } & D band & \multicolumn{2}{c}{$\mathrm{G}$ band $\left[\mathrm{cm}^{-1}\right]$} & \multirow{2}{*}{$I_{\mathrm{D}} / I_{\mathrm{G}}$} & $I_{\mathrm{G}-} / I_{\mathrm{G}+}$ \\
& {$\left[\mathrm{cm}^{-1}\right]$} & $\mathrm{G}-$ & $\mathrm{G}+$ & & \\
\hline Green $532 \mathrm{~nm}(2.33 \mathrm{eV})$ & 1321 & 1552 & 1577 & 0.008 & 0.29 \\
Red $633 \mathrm{~nm}(1.96 \mathrm{eV})$ & 1312 & 1551 & 1579 & 0.004 & 1.23 \\
\hline
\end{tabular}

for both products indicating the presence of the high quality SWCNTs (Tables 3 and 4), while the laser wavelength has no significant influence on this ratio. $G$ band is divided into two bands G- and G+: the G- is characteristic for vibrations in the circumferential direction and $\mathrm{G}+$ is characteristic for vibrations along the nanotubes axis. Their ratio $I_{\mathrm{G}-} / I_{\mathrm{G}+}$ gives information about the conducting character of the SWCNTs [29]. Using the $532 \mathrm{~nm}$ laser, for our ablation product and for the commercial one, this ratio is lower than 1 indicating the presence of semiconducting type, while when the $633 \mathrm{~nm}$ laser was used this ratio became higher than 1 indicating the presence of metallic type (Tables 3 and 4).

3.1.3. Kataura Plot Analysis. Kataura plot is a graph correlating the band gaps energy of the carbon nanotubes with their diameters [30]. A carbon nanotube can be metallic or semiconducting depending on its diameter. Rao et al. 


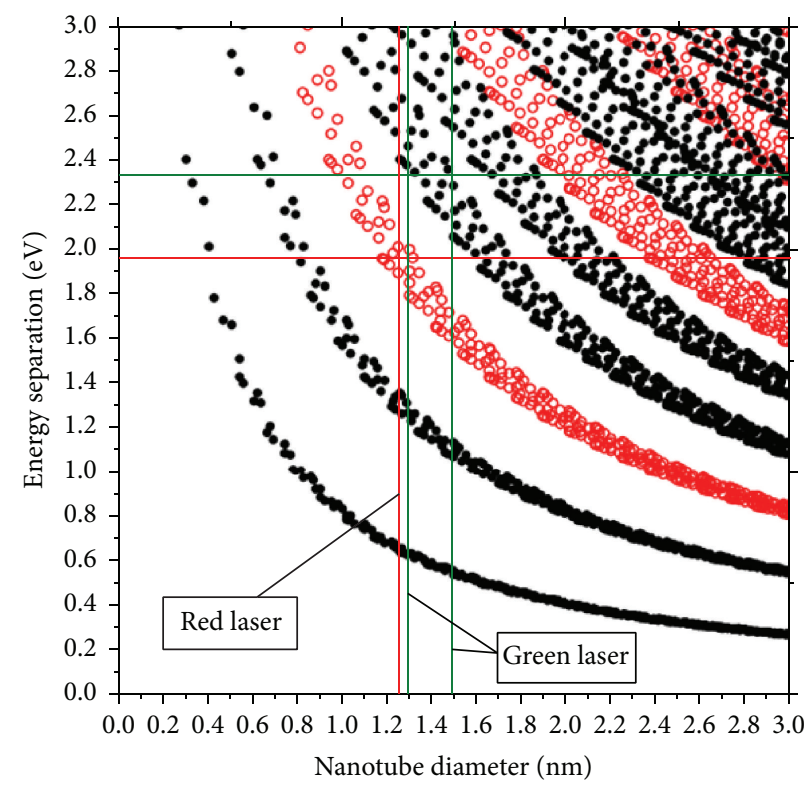

(a)

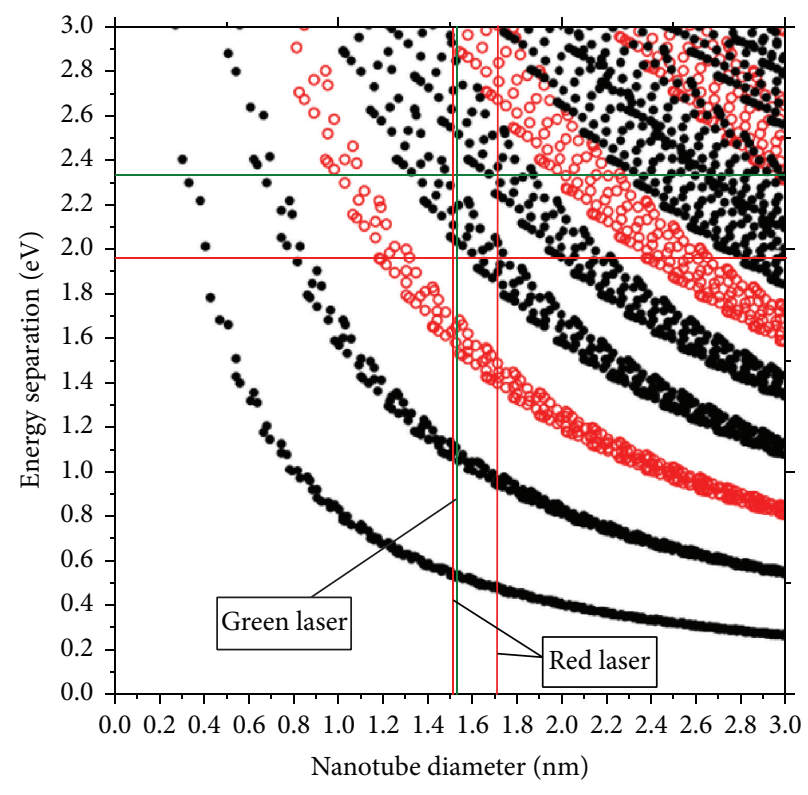

(b)

FIGURE 5: Kataura plot with black points indicating semiconductor nanotubes and red circles indicating metallic nanotubes. The horizontal green line indicates the excitation energy of the green laser $(2.33 \mathrm{eV})$, while the red line indicates the excitation energy of the red laser $(1.96 \mathrm{eV})$. The vertical green lines indicate the diameter distribution of the nanotubes of our ablation product obtained with the green laser and the red line with the red laser (a) and the commercial nanotubes from Sigma obtained with the green laser and the red line with the red laser (b) [33].

have shown that the Raman spectrum at a given wavelength is strongly influenced by the resonance Raman effect [31]. Raman scattering in SWCNTs is resonant, only when the band gap of the nanotubes is equal to the exciting laser energy $[32,33]$. However, this resonance effect in nanotubes is influenced by the conducting character; thus, we can identify the conducting character of the SWCNTs obtained during ablation by performing an interpolation in the Kataura plot of the estimated diameters with the laser excitation energies for our product and for the commercial one.

According to Kataura plot the commercial product contains semiconducting SWCNTs, while our ablation product indicates the presence of both types: semiconducting and metallic SWCNTs (Figure 5). By modifying the diameter of the SWCNTs we could move from a zone of semiconducting nanotubes to a zone of metallic ones; therefore, the conducting character of the SWCNTs could be changed.

\subsection{Scanning Electron Microscopy and Transmission Electron} Microscopy Analysis. The SEM image of the raw product soot (Figure 6) shows the presence of the SWCNTs bundles surrounded by the metal catalyst and amorphous carbon particles. For TEM imaging, the raw ablation product was dispersed in dimethylformamide (DMF) (Sigma-Aldrich), using an ultrasonic bath for 8 hours to get good dispersion. The TEM images were obtained with Philips-EM 410 TEM instrument (Figure 7) showing that the SWCNTs in the raw ablation product were grouped in micrometer-long bundles of different diameters, along the metal catalysts particles, graphite, and amorphous carbon, also present in the product.

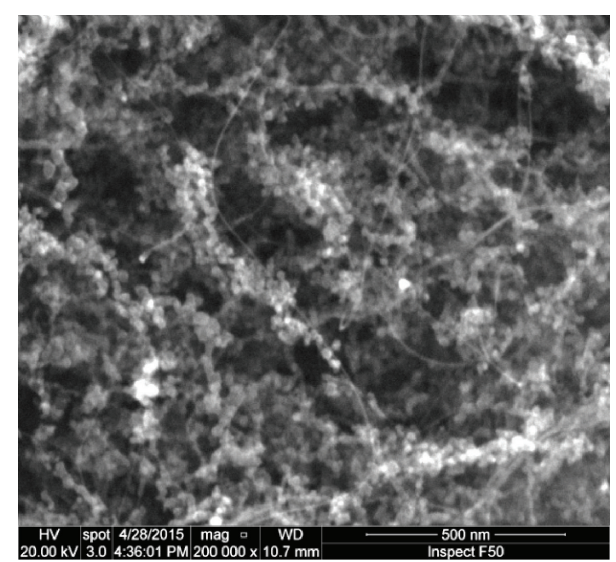

FIGURE 6: Scanning electron microscopy (SEM) image of the raw product synthesized by a KrF excimer laser ablation of the target.

The SEM and TEM micrographs support the Raman analysis data confirming the presence of the SWCNTs and low content of amorphous carbon.

3.3. Thermogravimetric Analysis. The thermogravimetric analysis (TGA) of the ablation product was carried out in synthetic air with a temperature rate of $5^{\circ} \mathrm{C} / \mathrm{min}$ using an STA-8000 Perkin Elmer instrument (Figure 8). TGA curves were recorded for the ablation product and ablated and nonablated sides of the target (Figure $8(\mathrm{a}, \mathrm{b}$, and $\mathrm{c})$ ). The TGA curve of the ablation product shows a burning slope centered around $400^{\circ} \mathrm{C}$, while nonablated target shows a slope 

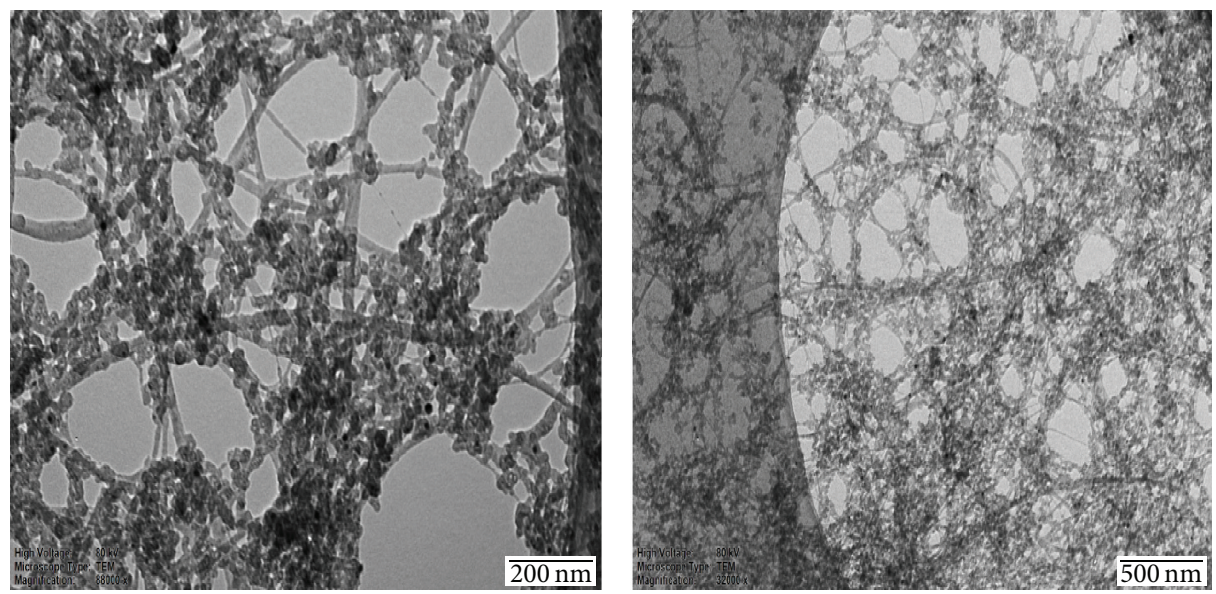

FIgURE 7: Transmission electron microscopy (TEM) images of the ablation product.

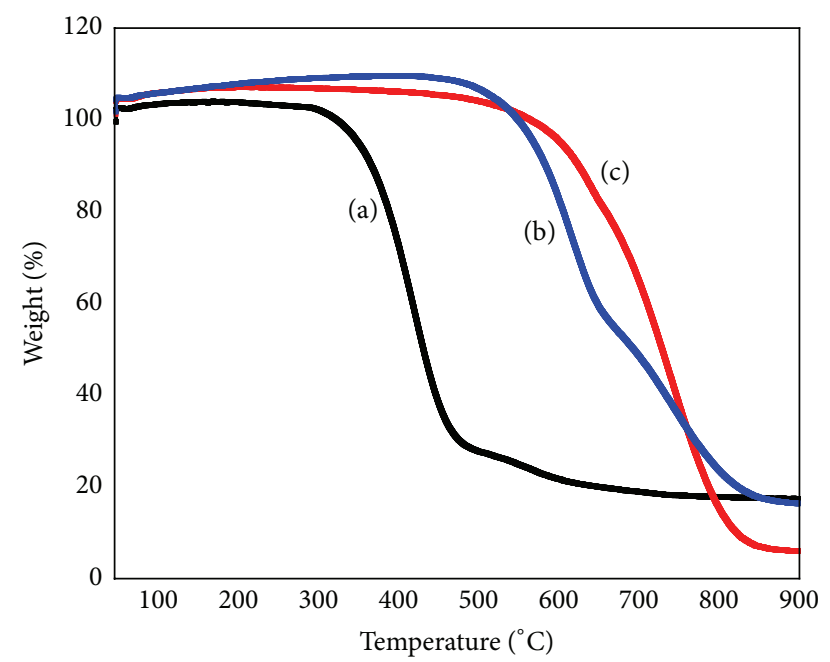

FIGURE 8: TGA curve recorded in air: (a) the ablation product, (b) ablated side of the target, and (c) nonablated target, respectively.

centered around $700^{\circ} \mathrm{C}$ proving that a new product was formed during the laser ablation. The same residual mass resulted from the ablation product as for the ablated side of the target (17.6\%), showing that the product preserves the same stoechiometry of the metal catalyst as the target from where it comes from. Also the residual mass of the ablated side of the target is higher than that of the nonablated side, showing that during ablation an increase of the metal content at the surface of the target has occurred.

The TGA curve in Figure 8(a) indicates that most of the weight loss occurred in the temperature range of $350-450^{\circ} \mathrm{C}$, where the SWCNTs burning took place. The $70 \%$ weight loss indicates a $70 \%$ SWCNTs production yield. Also multiple products are present in the ablation product like fullerenes (7-8\%) which burn between 500 and $600^{\circ} \mathrm{C}$, followed by the metal catalyst particles. TGA analysis confirms the presence of very low amount of amorphous carbon, fact revealed by the other analysis methods, Raman and TEM.

\section{Conclusion}

In the present work we have shown the production of high quality SWCNTs using krypton atmosphere by $\mathrm{KrF}$ excimer laser ablation. The SWCNTs were obtained with a high yield of $70 \%$. The obtained SWCNTs are a mixture of semiconducting and metallic types; also they are micrometers long with diameters distribution of 1.26 and $1.49 \mathrm{~nm}$. The ablation product preserves the same stoechiometry of metal catalyst as the target from where it comes. The quality of our product is comparable with the top quality of commercial SWCNTs. The quality of the produced SWCNTs by this method was confirmed by Raman, TGA, and TEM analysis showing very low content of amorphous carbon and defects in the structure of the nanotubes. Also TGA curve indicated low content of amorphous carbon and fullerenes.

\section{Conflict of Interests}

The authors declare that there is no conflict of interests regarding the publication of this paper.

\section{Acknowledgments}

This work was supported by Romanian Ministry of Education and by Executive Agency for Higher Education, Research, Development and Innovation Funding, under Projects PCCA 2-nr. 166/2012 and ENIAC 03/2013. J. AlZanganawee acknowledges the support from the Ministry of the Higher Education and Scientific Research of Iraq.

\section{References}

[1] S. Iijima, "Helical microtubules of graphitic carbon," Nature, vol. 354, no. 6348, pp. 56-58, 1991.

[2] S. Iijima and T. Ichihashi, "Single-shell carbon nanotubes of 1nm diameter," Nature, vol. 363, no. 6430, pp. 603-605, 1993.

[3] P. R. Bandaru, "Electrical properties and applications of carbon nanotube structures," Journal of Nanoscience and Nanotechnology, vol. 7, no. 4-5, pp. 1239-1267, 2007. 
[4] R. S. Ruoff and D. C. Lorents, "Mechanical and thermal properties of carbon nanotubes," Carbon, vol. 33, no. 7, pp. 925-930, 1995.

[5] J. Hone, M. C. Llaguno, M. J. Biercuk et al., "Carbon nanotubes, thermal properties of carbon nanotubes and nanotubes-based materials," Applied physics A, vol. 74, no. 3, pp. 339-343, 2002.

[6] A. Masotti and A. Caporali, "Preparation of magnetic carbon nanotubes (Mag-CNTs) for biomedical and biotechnological applications," International Journal of Molecular Sciences, vol. 14, no. 12, pp. 24619-24642, 2013.

[7] K. Besteman, J.-O. Lee, F. G. M. Wiertz, H. A. Heering, and C. Dekker, "Enzyme-coated carbon nanotubes as single-molecule biosensors," Nano Letters, vol. 3, no. 6, pp. 727-730, 2003.

[8] J. Li, Y. Lu, Q. Ye, M. Cinke, J. Han, and M. Meyyappan, "Carbon nanotube sensors for gas and organic vapor detection," Nano Letters, vol. 3, no. 7, pp. 929-933, 2003.

[9] T. Uchihashi, N. Choi, M. Ashino, Y. Sugawara, H. Nishijima, and S. Akita, "Carbon-nanotubes tip for highly-reproducible imaging of deoxyribonucleic acid helical turns by noncontact atomic force microscopy," Japanese Journal of Applied physics, vol. 39, no. 8, pp. 667-889, 2000.

[10] J. Li, C. Papadopoulos, and J. Xu, "Growing Y-junction carbon nanotubes," Nature, vol. 402, no. 6759, pp. 253-254, 1999.

[11] D. Dorobantu, P. Bota, M. Badea, I. Boerasu, D. Bojin, and M. Enachescu, "High quality and reliable caerbon Nano-structures used for 3rd generation of solar cells," in Proceedings of the 37th Annual Congress of the American Romanian Academy of Arts and Sciences (ARA '13), Chişinău, Moldova, June 2013.

[12] C. Liu, Y. Y. Fan, M. Liu, H. T. Cong, H. M. Cheng, and M. S. Dresselhaus, "Hydrogen storage in single-walled carbon nanotubes at room temperature," Science, vol. 286, no. 5442, pp. 1127-1129, 1999.

[13] J. Kong, A. M. Cassell, and H. Dai, "Chemical vapor deposition of methane for single-walled carbon nanotubes," Chemical Physics Letters, vol. 292, no. 4-6, pp. 567-574, 1998.

[14] Z. Shi, Y. Lian, F. H. Liao et al., "Large scale synthesis of singlewall carbon nanotubes by arc-discharge method," Journal of Physics and Chemistry of Solids, vol. 61, no. 7, pp. 1031-1036, 2000.

[15] W. K. Maser, E. Muñoz, A. M. Benito et al., "Production of high-density single-walled nanotube material by a simple laserablation method," Chemical Physics Letters, vol. 292, no. 4-6, pp. 587-593, 1998.

[16] T. Guo, P. Nikolaev, A. Thess, D. T. Colbert, and R. E. Smalley, "Catalytic growth of single-walled manotubes by laser vaporization," Chemical Physics Letters, vol. 243, no. 1-2, pp. 49-54, 1995.

[17] D. Nishide, H. Kataura, S. Suzuki, K. Tsukagoshi, Y. Aoyagi, and Y. Achiba, "High-yield production of single-wall carbon nanotubes in nitrogen gas," Chemical Physics Letters, vol. 372, no. 1-2, pp. 45-50, 2003.

[18] A. Thess, R. Lee, P. Nikolaev et al., "Crystalline ropes of metallic carbon nanotubes," Science, vol. 273, no. 5274, pp. 483-487, 1996.

[19] M. Kusaba and Y. Tsunawaki, "Production of single-wall carbon nanotubes by a $\mathrm{XeCl}$ excimer laser ablation," Thin Solid Films, vol. 506-507, pp. 255-258, 2006.

[20] G. Radhakrishnan, P. M. Adams, and L. S. Bernstein, "Plasma characterization and room temperature growth of carbon nanotubes and nano-onions by excimer laser ablation," Applied Surface Science, vol. 253, no. 19, pp. 7651-7655, 2007.

[21] V. Le Borgne, B. Aïssa, M. Mohamedi, Y. A. Kim, M. Endo, and M. A. El Khakani, "Pulsed KrF-laser synthesis of singlewall-carbon-nanotubes: effects of catalyst content and furnace temperature on their nanostructure and photoluminescence properties," Journal of Nanoparticle Research, vol. 13, no. 11, pp. 5759-5767, 2011.

[22] P. M. Bota, D. Dorobantu, I. Boerasu, D. Bojin, and M. Enachescu, "Synthesis of single-wall carbon nanotubes by excimer laser ablation," Surface Engineering and Applied Electrochemistry, vol. 50, no. 4, pp. 294-299, 2014.

[23] H. Kataura, Y. Kumazawa, Y. Maniwa et al., "Diameter control of single-walled carbon nanotubes," Carbon, vol. 38, no. 11, pp. 1691-1697, 2000.

[24] P. M. Bota, D. Dorobantu, I. Boerasu, D. Bojin, and M. Enachescu, "New laser ablation chamber for producing carbon nanomaterials using excimer laser," Materials Research Innovations, vol. 19, no. 1, pp. 33-39, 2015.

[25] N. Braidy, M. A. El Khakani, and G. A. Botton, "Single-wall carbon nanotubes synthesis by means of UV laser vaporization," Chemical Physics Letters, vol. 354, no. 1-2, pp. 88-92, 2002.

[26] J. Maultzsch, H. Telg, S. Reich, and C. Thomsen, "Radial breathing mode of single-walled carbon nanotubes: optical transition energies and chiral-index assignment," Physical Review B: Condensed Matter and Materials Physics, vol. 72, no. 20, Article ID 205438, 2005.

[27] H. Kataura, Y. Miyata, and K. Mizuno, "Purity and defect characterization of single-wall carbon nanotubes using raman spectroscopy," Journal of Nanomaterials, vol. 2011, Article ID 786763, 7 pages, 2011.

[28] V. M. Irurzun, M. P. Ruiz, and D. E. Resasco, "Raman intensity measurements of single-walled carbon nanotube suspensions as a quantitative technique to assess purity," Carbon, vol. 48, no. 10, pp. 2873-2881, 2010.

[29] R. D. Rodriguez, M. Toader, S. Hermann et al., "Nanoscale optical and electrical characterization of horizontally aligned single-walled carbon nanotubes," Nanoscale Research Letters, vol. 7, article 682, 6 pages, 2012.

[30] H. Kataura, Y. Kumazawa, Y. Maniwa et al., "Optical properties of single-wall carbon nanotubes," Synthetic Metals, vol. 103, no. 1-3, pp. 2555-2558, 1999.

[31] A. M. Rao, E. Richter, S. Bandow et al., "Diameter-selective Raman scattering from vibrational modes in carbon nanotubes," Science, vol. 275, no. 5297, pp. 187-190, 1997.

[32] C. Fantini, A. Jorio, M. Souza, M. S. Strano, M. S. Dresselhaus, and M. A. Pimenta, "Optical transition energies for carbon nanotubes from resonant raman spectroscopy: environment and temperature effects," Physical Review Letters, vol. 93, no. 14, Article ID 147406, 2004.

[33] S. G. Chou, G. G. Samsonidze, G. Dreselhaus, and M. S. Dreselhau, "Stokes and anti-stokes Raman spectra of small-diameter isolated carbon nanotubes," Physical Review B, vol. 69, no. 11, Article ID 115428, 2004.

[34] http://www.photon.t.u-tokyo.ac.jp/ maruyama/kataura/kataura.html. 

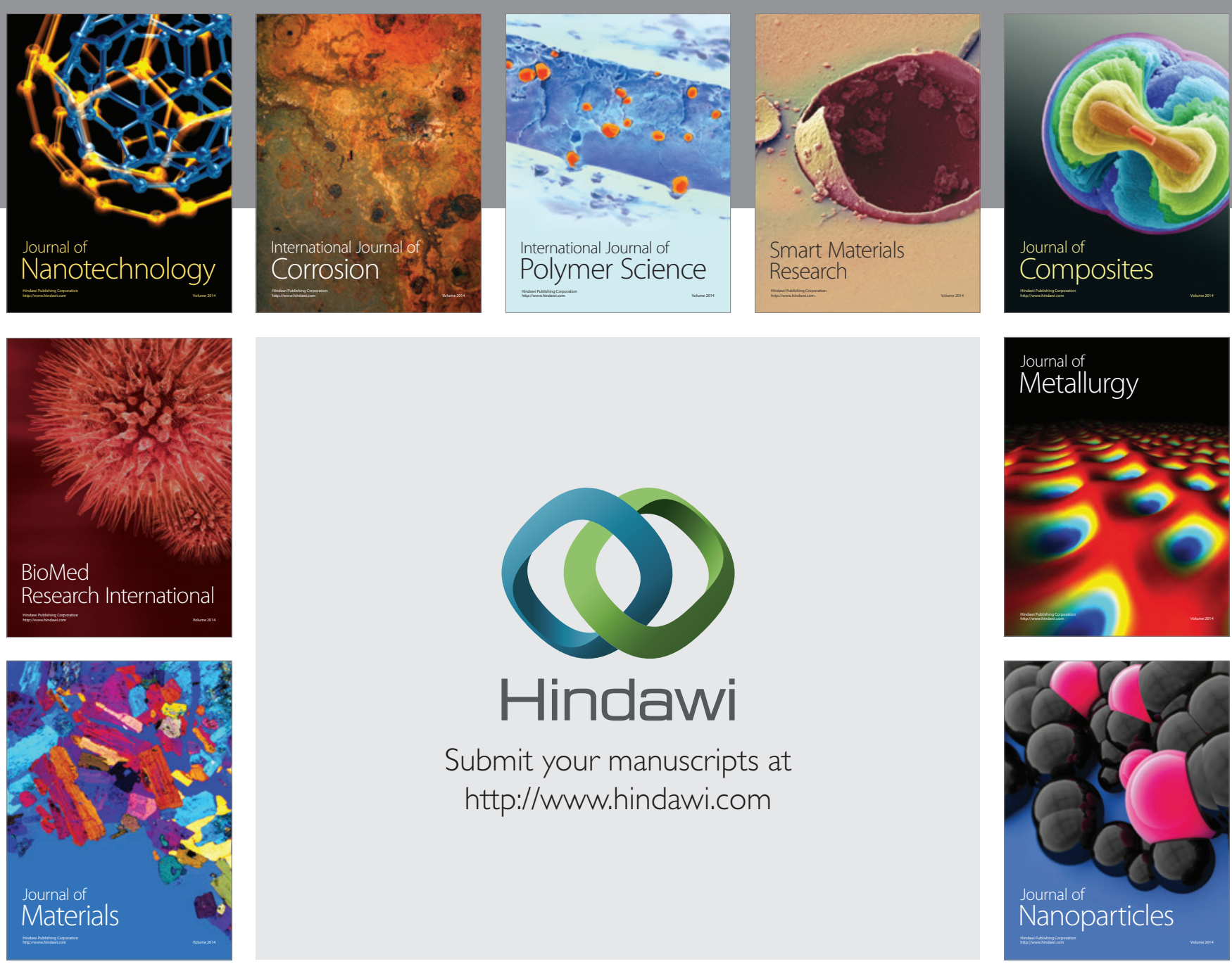

Submit your manuscripts at http://www.hindawi.com
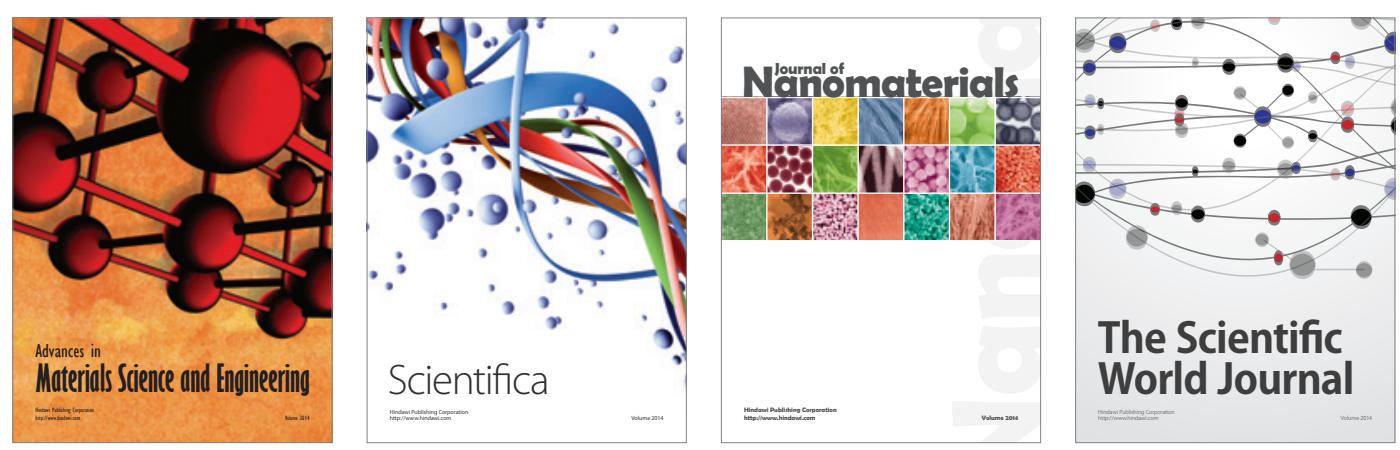

\section{The Scientific World Journal}
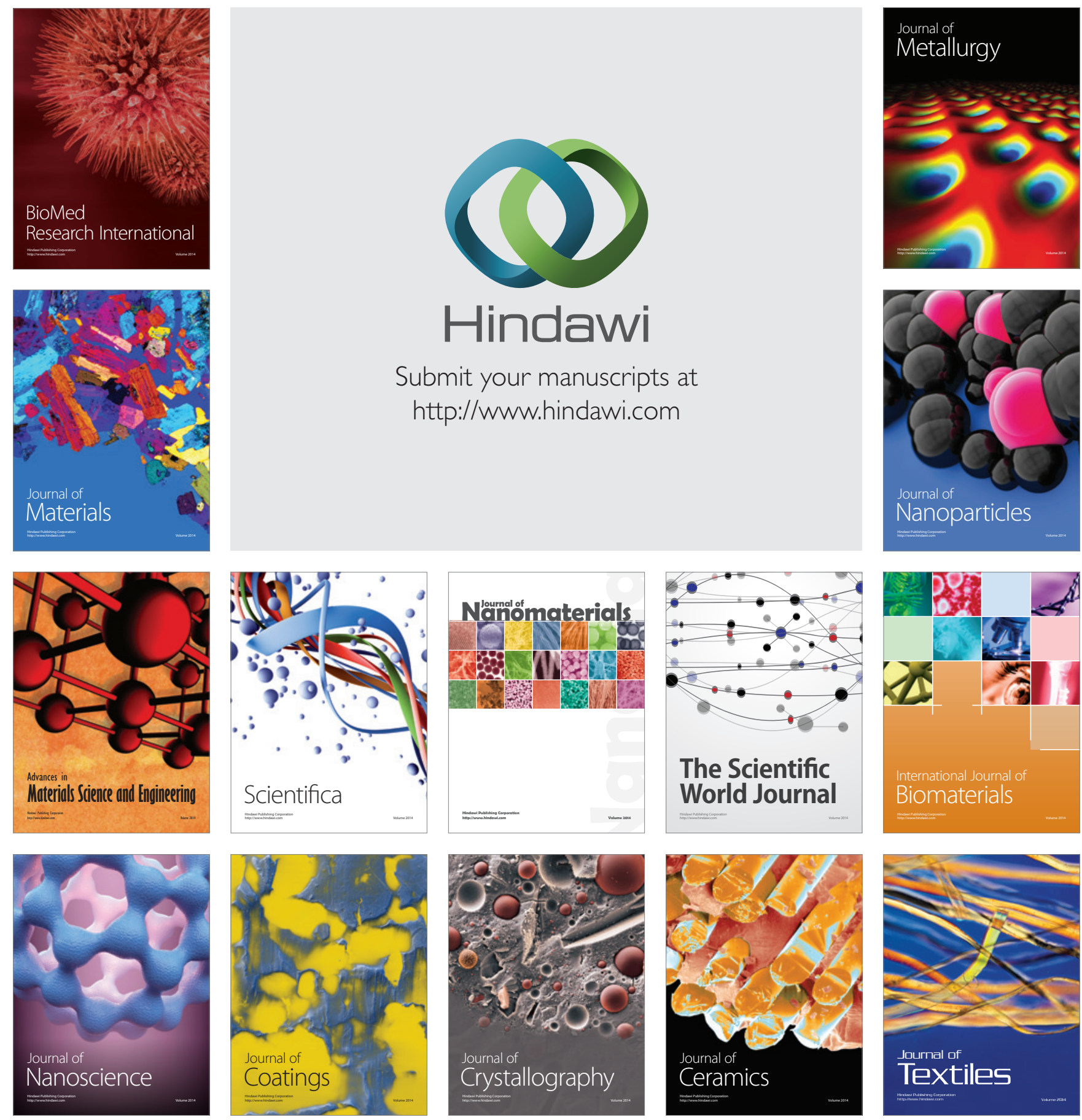